DOI: 10.17707/AgricultForest.65.4.03

\author{
Fokion PAPATHANASIOU*, Fotini PAPADOPOULOU, \\ Ioannis MYLONAS, Elisavet NINOU, Ioannis PAPADOPOULOS ${ }^{1}$
}

\title{
SINGLE-PLANT SELECTION AT ULTRA-LOW DENSITY OF FIRST GENERATION LINES OF THREE BEAN CULTIVARS UNDER WATER STRESS
}

\begin{abstract}
SUMMARY
Nil-competition (ultra-low plant density) has been asserted to highlight individual genotypes of high yielding potential. This was tested preliminary on three determinate type bean varieties (Phaseolus vulgaris L.), two genetically non-uniform and with unstable yields Greek cultivars, Iro and Pirgetos and a "Great northern" type imported variety. Single-plant selection under ultra-low density (interplant distance of $100 \mathrm{~cm}$ ) was performed in a honeycomb design experiment established during 2017 in the main farm of the University of Western Macedonia in Florina. Eighteen high yielding plants were selected and seed of each constituted a separate first generation line. In 2018, progeny evaluation was conducted in two R21 honeycomb design trials under normal and deficit irrigation treatments respectively. Compared to the original variety Iro, four of the high yielding progeny lines had higher yield plant ${ }^{-1}$ (by 20 to 39\%) under water deficit with two being significantly different, where for the variety Pyrgetos only one first generation sister line significantly outperformed the original cultivar by $28 \%$. Water stress affected significantly total chlorophyll content measured at 10 day intervals from start of flowering until physiological maturity with the best performing progeny lines showing higher chlorophyll concentrations especially during the seed filling stage. Significant differences between progeny lines and the original varieties were also shown on $\mathrm{CO}_{2}$ assimilation rate under water deficit especially within the genotype Iro. Further research is needed so that any existing variation is beneficially exploited.

Keywords: Ultra-low plant density, Water stress, Chlorophyll concentration, $\mathrm{CO}_{2}$ assimilation rate.

\section{INTRODUCTION}

Common bean (Phaseolus vulgaris L.) is the most important food legume, representing near $50 \%$ of grain legumes for human consumption and a significant

\footnotetext{
${ }^{1}$ Fokion Papathanasiou *(corresponding author: fokionp@florina.teiwm.gr; fokionp@gmail.com), Fotini Papadopoulou, Ioannis Papadopoulos, University of Western Macedonia, Department of Agriculture, Terma Kontopoulou, 53100 Florina, GREECE; Ioannis Mylonas, Hellenic Agricultural Organization-Demeter, Institute of Plant Breeding and Plant Genetic Resources, Thermi, GR-57001 Thessaloniki, GREECE; Elisavet Ninou, Hellenic Agricultural OrganizationDemeter, Industrial and Fodder Crops Institute, Larissa, GREECE Paper presented at the $10^{\text {th }}$ International Scientific Agricultural Symposium "AGROSYM 2019". Notes: The authors declare that they have no conflicts of interest. Authorship Form signed online.
} 
source of high quality and low cost protein (Beede et al., 2013). Common bean is the most significant among the other pulses in Greece with increased cultivated areas in recent years (Kargiotidou et al., 2019). Modern agriculture depends by far on uniform crop varieties in order to meet a growing demand for food by the world's population, and in most cases several landraces have progressively been replaced by elite cultivars satisfying the farmers and consumer's needs (Mavromatis et al., 2007). The existence of genetic heterogeneity in Greek genotypes is offered for plant selection with methods of classical improvement and main criterion plant yield (Papadopoulos et al., 2007). An intracultivar single-plant selection under ultra-low density has been extensively used to exclude plant-to-plant interference for resources as nil-competition boosts phenotypic expression and erases the masking effects induced by the negative relationship between yielding and competitive ability (Tokatlidis, 2015). This is making selection of desirable genotypes within a narrow gene pool and divergent environments applicable (Vlahostergios et al., 2018).

Climate change is inflicting a high impact on agriculture by altering the spatial and temporal distribution of rainfall, which limits water availability (Crimmins et al., 2011). Water deficit is a major limiting factor for crop productivity worldwide resulting in significant seed yield reductions across $60 \%$ of global bean production areas (Soureshjani et al., 2018). Reduced water availability results in lower water potential of plant tissues which decreases stomatal closure, leading to a reduction of $\mathrm{CO}_{2}$ availability and, consequently, lower photosynthesis and transpiration rates (Teran and Singh, 2002; Bota et al., 2004). Chlorophyll content of common bean is also reduced as a result of the degradation caused by drought conditions (Beede et al., 2013), and is directly related to biomass accumulation. These responses depend on the intensity of the stress, the plant genotype, and the plant developmental stage at stress incidence, among other factors (Beebe et al., 2013).

The necessity to tackle this challenge has led to breeding and developing new varieties adapted to a continuously changing environment either exploiting intraspecific variability or by transferring genes from closely related wild species adapted to low irrigation (Martinez et al., 2007). Extensive evidence exists to show that genetic resources for drought tolerance have potential for breeder programs (Andrade et al., 2016; Farooq et al., 2017). However most bean genetic diversity and bean populations are underutilized because of the difficulties that exist with the evaluation of physiological drought response dynamics in many cultivars.

The main objective of the present study was to evaluate high-yielding first generation lines of three different bean varieties selected at ultra-low density under water deficit conditions during anthesis and seed-filling growth stage. The range of variation in agronomic and physiological parameters that could exist may be utilized for identifying and developing improved genotypes which could perform better under adverse conditions. 


\section{Plant material and experimentation}

Three common bean determinate type genotypes, two Greek cultivars Iro and Pirgetos developed by the Hellenic Industrial and Fodder Crops Institute and an imported one Great-northern type constituted the source material. During 2017, single-plant selection was performed under ultra-low density (interplant distance of $100 \mathrm{~cm}$ ) in a honeycomb design experiment in the main farm of the University of Western Macedonia in Florina as described in previous work (Papathanasiou et al., 2018). Eighteen high yielding plants were selected and seed of each constituted a separate first generation line. The selected first generation lines were coded hereafter GNTY1 to GNTY6, IR1 to IR6 and PIR1 to PIR6 according to the original genotype. During the 2018 season, approximately 50 plants per first generation line were assessed in two R21 honeycomb design trials under normal and deficit irrigation treatments respectively using the original genotypes as controls. The experiments were sown on $9^{\text {th }}$ of May in the experimental farm of the University of W. Macedonia in Florina Greece $\left(40^{\circ} 46^{\prime} \mathrm{N}, 21^{\circ} 22^{\prime} \mathrm{E}, 707 \mathrm{~m}\right.$ asl), in a sandy loam soil with $\mathrm{pH}$ 6.3, organic matter content $14.0 \mathrm{~g} \mathrm{~kg}^{-1}, \mathrm{~N}-\mathrm{NO}_{3} 100 \mathrm{mg} \mathrm{kg}^{-1}, \mathrm{P}$ (Olsen) $50.3 \mathrm{mg} \mathrm{kg}^{-1}$ and $\mathrm{K} 308 \mathrm{mg} \mathrm{kg}^{-1}$ and water holding capacity $21.8 \%$ (0 to $30 \mathrm{~cm}$ depth). The ultra-low density of 1.2 plants $/ \mathrm{m}^{2}$ was used i.e. single-plant hills were spaced 100 $\mathrm{x} 100 \mathrm{~cm}$ apart. Two or three seeds were sown in each hill and later thinned to obtain single-plant hills. A total of $400 \mathrm{Kg} / \mathrm{ha} 0-20-0$ and $200 \mathrm{Kg} / \mathrm{ha} 11-15-15$ fertilizers were applied at planting, while additional $\mathrm{N}$ (50 g per plant of a 27-0-0 fertilizer) was top-dressed when plants had reached the appropriate developmental stage. Complete weed control was obtained by tilling and hand.

\section{Irrigation treatments}

The normal irrigation received a full irrigation treatment, while deficit irrigation was $50 \%$ of the normal to simulate drought stress. A drip-irrigation water supply system of $4 \mathrm{~L} \mathrm{~h}^{-1}$ was established along every row, with emitters spaced at $40 \mathrm{~cm}$ intervals. Irrigation scheduling was based on bean evapotranspiration $\left(\mathrm{ET}_{\mathrm{c}}\right)$ and was applied when the crop evapotranspiration rate $\mathrm{ET}_{\mathrm{c}}-\mathrm{P}$ (rainfall) reached $30 \mathrm{~mm}$. Soil water content at this level was approximately $70 \%$ of field capacity, which is considered adequate for plant growth during all stages. The $\mathrm{ET}_{\mathrm{c}}$ was calculated from climatic parameters measured daily from a meteorological station located adjacent to the experimental site and was used to calculate the reference evapotranspiration rate $\left(\mathrm{ET}_{\mathrm{o}}\right)$ using the Penman-Monteith method (Allen et al., 1998). The $\mathrm{ET}_{\mathrm{c}}$, which is the product of $\mathrm{ET}_{\mathrm{o}}$ and the crop coefficient $\left(\mathrm{K}_{\mathrm{c}}\right)$, was calculated using values for bean $\mathrm{K}_{\mathrm{c}}$ adjusted to Greek conditions $\left(\mathrm{K}_{\text {cini }}=0.35, \mathrm{~K}_{\text {cropd }}=0.70, \mathrm{~K}_{\mathrm{cmid}}=\right.$ 1.10 , and $K_{\text {cend }}=0.30$ ) for growth stages of 15/40/75/95 d after emergence.

\section{Chlorophyll and gas-exchange measurements}

Total chlorophyll content was measured with a hand-held dual-wavelength meter (SPAD 502, Chlorophyll meter, Minolta Ltd., Japan) at five 10-day intervals from start of flowering until physiological maturity (SPAD1 to SPAD5) 
in six plants of each genotype in normal and deficit irrigation conditions. A portable photosynthesis system that measures $\mathrm{CO}_{2}$ uptake (LI-6400 XT, Li-Cor, USA) equipped with a square $\left(6.25 \mathrm{~cm}^{2}\right)$ chamber was used for determinations of $\mathrm{CO}_{2}$ assimilation rate $(\mathrm{A})$, transpiration rate $(\mathrm{E})$ and stomatal conductance to water vapour $\left(g_{s}\right)$ during the seed filling period. Leaf gas exchange was measured in the middle leaflet of a fully expanded trifoliate leaf close to the top of the plants. Measurements were performed on the same six plants of each genotype that chlorophyll measurements were taken from 09:00-12:00 in the morning to avoid high vapor-pressure deficit and photoinhibition at midday.

\section{Harvest and statistical analysis}

Plants were harvested individually and seed yield was measured at the physiological maturity stage and recorded at a per-plant basis for both normal and deficit irrigation treatments. Comparison of means was conducted by Least Significance Difference Test (LSD) after analysis of Variance (ANOVA), for completely random design.

\section{RESULTS AND DISCUSSION}

Mean yield and coefficient of variation (CV\%) for seed yield plant ${ }^{-1}(\mathrm{~g})$ at ultra-low density under normal and deficit irrigation for the first generation lines compared to the three original genotypes (GNTY, IR and PIR) are presented in Table 1. For the genotype GNTY the six high-yielding first generation lines performed equally with the original genotype under the deficit irrigation treatment with no significant differences in yield plant ${ }^{-1}$ whereas under normal irrigation the control showed higher values than all of its progenies. Compared to the original variety Iro, almost all progeny lines had significantly higher yields under normal irrigation and four of them showed higher yield plant ${ }^{-1}$ (by 20 to $39 \%$ ) under water deficit with two being significantly different. The first generation sister lines IR1 and IR6 yielded on average 121,2 and $117 \mathrm{~g} \mathrm{plant}^{-1}$ and showed a CV of 45,5 and $50 \%$ respectively. The respective values of the mother genotype IR-control under the same irrigation conditions were 86,8 $\mathrm{g}$ plant $^{-1}$ and CV of 55,6\%. Similarly for the variety Pirgetos all progeny lines yielded higher than the control under normal water regime but only one first generation sister line significantly outperformed the original cultivar by $28 \%$ under the deficit irrigation. The line PIR5 showed mean yield plant ${ }^{-1} 120,4 \mathrm{~g}$ and CV 52,6\% compared to the PIR-control which yielded $94 \mathrm{~g}$ with a similar CV of $52,6 \%$. This is in agreement with other studies where under adverse conditions such as high temperatures and increased biotic stress first generation sister lines of bean and/or other legumes such as lentils, outperformed the original genotypes under ultra-low density (Papadopoulos et al., 2004; Vlahostergios et al., 2018). The CV values under the ultra-low density for seed yield plant ${ }^{-1}$ revealed a moderate spatial heterogeneity under deficit irrigation for all the genotypes tested. This is desirable because phenotypic screening and breeding for high yield is expected to ultimately select for potentially tolerant to water stress genotypes (Tokatlidis, 2015). 
Physiological parameters such as mean chlorophyll content, assimilation rate $A$, stomatal conductance to water vapour $g_{s}$ and transpiration rate $E$ under normal and deficit irrigation are shown in Table 2 for all genotypes evaluated. Reduction in water supply was associated with decreased chlorophyll content (SPAD) during the seed filling stage. The high-yielding progenies IR1, IR5 and IR6 had significantly higher values than the IR-control during the late seedfeeling stage (SPAD 5). Similar results were observed for the line PIR5 with significant differences only during the early seed-filling stage (SPAD4). Chlorophyll content has been proposed as a good indicator of green color and the stay green characteristic under water stress is a commonly observed phenomenon (Fotonat et al., 2007).

Table 1. Mean yield and coefficient of variation (CV\%) for grain yield plant ${ }^{-1}$ (g) at ultra-low density under normal and deficit irrigation for the first generation lines originating from the three genotypes (GNTY, IR and PIR) and the control.

\begin{tabular}{ccccc}
\hline \multicolumn{2}{c}{ Normal Irrigation } & \multicolumn{2}{c}{ Deficit Irrigation } \\
\hline lines & $\begin{array}{c}\text { Yield } \\
\text { g plant }^{-1}\end{array}$ & CV\% & $\begin{array}{c}\text { Yield } \\
\text { g plant }^{-1}\end{array}$ & CV\% \\
\hline GNTY1 & $147,6^{*}$ & 45,2 & 91,6 & 55,6 \\
GNTY2 & 158,3 & 44,2 & 82,8 & 66,7 \\
GNTY3 & 149,9 & 55,6 & 90,0 & 83,3 \\
GNTY4 & 152,6 & 43,3 & 92,1 & 62,5 \\
GNTY5 & 153,4 & 44,4 & 91,0 & 58,8 \\
GNTY6 & 164,3 & 44,2 & 98,4 & 62,5 \\
GNTY-Control & $\mathbf{1 7 6 , 7}$ & $\mathbf{3 7 , 6}$ & $\mathbf{9 0 , 6}$ & $\mathbf{5 8 , 8}$ \\
IR1 & $161,8^{* *}$ & 40,5 & $121,2 * *$ & 45,5 \\
IR2 & 147,3 & 51,0 & 100,5 & 43,5 \\
IR3 & $158,3^{*}$ & 48,8 & 112,7 & 62,5 \\
IR4 & $152,5^{*}$ & 40,7 & 82,4 & 58,8 \\
IR5 & $177,4^{* *}$ & 48,3 & 104,6 & 55,6 \\
IR6 & $178,0^{* *}$ & 50,0 & $117,0 *$ & 50,0 \\
IR-Control & $\mathbf{1 1 5 , 4}$ & $\mathbf{5 6 , 5}$ & $\mathbf{8 6 , 8}$ & $\mathbf{5 5 , 6}$ \\
PIR1 & 176,7 & 34,7 & 96,0 & 71,4 \\
PIR2 & $158,5^{* *}$ & 46,3 & 84,6 & 58,8 \\
PIR3 & $153,7^{*}$ & 56,2 & 81,8 & 62,5 \\
PIR4 & 144,0 & 51,8 & 91,3 & 52,6 \\
PIR5 & $168,0^{* *}$ & 44,4 & $120,4 *$ & 52,6 \\
PIR6 & 141,9 & 44,2 & 97,9 & 55,6 \\
PIR-Control & $\mathbf{1 1 7 , 0}$ & $\mathbf{5 0 , 3}$ & $\mathbf{9 4}$ & $\mathbf{5 2 , 6}$ \\
\hline
\end{tabular}

*, ** Denotes significant superiority to the mother landrace (t test for independent means and different standard deviations at the levels $\mathrm{P}<0.05$ and $\mathrm{P}<0.01$ accordingly)

Compared to the original variety Iro the first generation sister lines IR1 and IR6 showed significantly lower reduction in A, $g_{s}$ and E. The higher stomatal 
conductance of these two progenies under the water deficit conditions led to an increased $\mathrm{CO}_{2}$ availability which had a direct positive effect on photosynthesis compared to the IR-control. Similar results have been reported by Soureshjani et al. (2018). Although the higher yielded progeny PIR5 had a better physiological response than the PIR-control no significant differences were observed.

Table 2. Mean chlorophyll content (SPAD 4 and 5) during early and late seedfilling stage at two intervals of 10 days, assimilation rate $\mathrm{A}\left(\square \mathrm{mol} \mathrm{CO} \mathrm{m}^{-2} \mathrm{~s}^{-1}\right)$, stomatal conductance to water vapour $\mathrm{g}_{\mathrm{s}}\left(\mathrm{mol}\right.$ of $\mathrm{H}_{2} \mathrm{O} \mathrm{m}^{-2} \mathrm{~s}^{-1}$ ) and transpiration rate $\mathrm{E}$ (mol of $\mathrm{H}_{2} \mathrm{O} \mathrm{m}^{-2} \mathrm{~s}^{-1}$ ) at ultra-low density under normal and deficit irrigation for the first generation lines originating from the three genotypes (GNTY, IR and PIR) and the control.

\begin{tabular}{|c|c|c|c|c|c|c|c|c|c|c|}
\hline \multirow{2}{*}{$\begin{array}{c}\text { First generatio } \\
\text { lines }\end{array}$} & \multicolumn{5}{|c|}{ Normal Irrigation } & \multicolumn{5}{|c|}{ Deficit Irrigation } \\
\hline & SPAD 4 & SPAD 5 & A & $g_{s}$ & $\mathbf{E}$ & SPAD4 & SPAD5 & A & $\mathbf{g}_{\mathrm{s}}$ & $\mathbf{E}$ \\
\hline GNTY1 & $39,22 *$ & $32,98 *$ & 13,78 & $0,360^{*}$ & 3,91 & 35,60 & 28,22 & 9,20 & 0,200 & 2,60 \\
\hline GNTY2 & 45,67 & 37,57 & 15,74 & 0,592 & 4,84 & $33,52 *$ & $25,35^{*}$ & 8,33 & $0,123^{*}$ & $2,16^{*}$ \\
\hline & 41,82 & $33,97 *$ & 92 & 4 & 4,35 & 5,87 & 26,92 & 7,47 & 0,138 & $2,26^{*}$ \\
\hline GNTY4 & 43,73 & 38,92 & 14,33 & 0,488 & 4,11 & 41,53 & 30,82 & 8,91 & $0,125^{*}$ & $2,38^{*}$ \\
\hline GNTY5 & $40,23^{*}$ & 34,47 & 16,85 & 0,513 & 5,62 & 38,98 & $23,93 *$ & 8,35 & $0,126^{*}$ & $2,19 *$ \\
\hline & & & & & 5,04 & 39,35 & $26,78^{*}$ & 9,75 & & 2,45 \\
\hline GNTY-Control & 44,68 & 37,40 & 16,07 & 0,462 & 4,92 & 39,48 & 31,70 & 10,49 & 0,218 & 3,34 \\
\hline IR1 & 39,32 & 34,50 & $16,20^{*}$ & 0,432 & 4,76 & 38,85 & $31,58^{*}$ & $12,56^{*}$ & $0,230^{*}$ & 2,53 \\
\hline IR & & & & & 3,8 & 5,68 & 9,63 & 8,92 & & 2,34 \\
\hline IR3 & 40,10 & 32,87 & 14,22 & 0,443 & 4,31 & 38,03 & 28,33 & $12,36^{*}$ & 0,188 & 2,81 \\
\hline IR4 & $43,12^{*}$ & 40,07 & 14,10 & 0,478 & 3,94 & 32,83 & 25,52 & 7,85 & 0,130 & 2,35 \\
\hline IR5 & $43,75^{*}$ & 37,50 & $19,36 *$ & 0,497 & 5,14 & $43,88^{*}$ & $30,93 *$ & 12,01 & 0,208 & 2,76 \\
\hline IR6 & 42,02 & 37,10 & $18,18^{*}$ & $0,525^{*}$ & 5,31 & 40,45 & $31,43^{*}$ & $12,81^{*}$ & $0,237^{*}$ & $3,29 *$ \\
\hline IR-Control & 39,15 & 32,43 & 11,59 & 0,390 & 4,36 & 36,87 & 26,02 & 8,90 & 0,138 & 2,33 \\
\hline PIR1 & $45,10^{*}$ & $38,83^{*}$ & $18,99 *$ & 0,502 & 5,16 & 34,75 & 28,55 & 10,70 & 0,153 & 2,41 \\
\hline PIR2 & $42,57 *$ & $36,27 *$ & 13,88 & 0,478 & 4,14 & 36,47 & 29,18 & 8,18 & 0,230 & 3,10 \\
\hline PIR3 & $41,92 *$ & 34,63 & 15,22 & 0,480 & 4,27 & $32,15^{*}$ & 27,08 & 8,69 & 0,182 & 2,49 \\
\hline PIR4 & $40,70^{*}$ & 34,37 & 13,57 & 0,488 & 4,00 & 37,45 & 31,32 & 10,17 & 0,203 & 2,84 \\
\hline PIR5 & $44,18^{*}$ & $36,25^{*}$ & 15,10 & 0,392 & 4,26 & $42,82^{*}$ & 30,13 & 11,88 & 0,213 & 2,74 \\
\hline PIR6 & $40,70^{*}$ & 32,28 & 13,85 & 0,475 & 4,81 & 40,95 & 28,63 & 11,30 & 0,173 & 2,91 \\
\hline PIR-Control & 37,12 & 32,05 & 13,96 & 0,600 & 4,57 & 37,58 & 28,43 & 11,02 & 0,155 & 2,58 \\
\hline
\end{tabular}

*, ** Denotes significant superiority to the mother landrace (t test for independent means and different standard deviations at the levels $\mathrm{P}<0.05$ and $\mathrm{P}<0.01$ accordingly) 


\section{CONCLUSIONS}

The results of this study demonstrate that there is intracultivar variation on seed yield under deficit irrigation during a thesis and seed filling stage within first generation sister lines. Also physiological traits were related to deficit irrigation tolerance which could assist in the identification of mechanisms underlying these adaptation processes and in the selection of improved genotypes of common bean. Further research is underway to confirm the results of the present study and to exploit further any existing variation.

\section{ACKNOWLEDGEMENTS}

Financial support of this project (project code 80164) by the Special Account for Research Grants of the University of Western Macedonia, Greece is gratefully acknowledged.

\section{REFERENCES}

Allen R.G., Pereira L.S., Raes D., Smith M. (1998). Crop evapotranspiration. Guidelines for computing crop water requirements. In: FAO Irrigation and Drainage Paper 56.

Andrade E.R., Ribeiro V.N., Azevedo C.V.G., Chiorato A.F., Williams T.C.R., Carbonell S.A.M. (2016). Biochemical indicators of drought tolerance in the common bean (Phaseolus vulgaris L.). Euphytica 210, 277-289.

Beebe S.E., Rao I.M., Blair M.W., Acosta-Gallegos J.A. (2013). Phenotyping common beans for adaptation to drought. Frontiers in Physiology 4, 1-20.

Bota J., Medrano H., Flexas J. (2004). Is photosynthesis limited by decreased Rubisco activity and RuBP content under progressive water stress? New Phytologist 162, 671-681.

Crimmins S.M., Dobrowski S.Z., Greenberg J.A., Abatzoglou J.T., Mynsberge, A.R. (2011). Changes in climatic water balance drive downhill shifts in plant species' optimum elevations. Science, m331(6015), 324-327.

Farooq M., Gogoi N., Barthakur S., Baroowa B., Bharadwaj N., Alghamdi S.S., Siddique K.H.M. (2017). Drought stress in grain legumes during reproduction and grain filling. Journal of Agronomy and Crop Science 203, 81-102.

Fotovat R., Valizadeh M., Toorchi M. (2007). Association between water-use efficiency components and total chlorophyll content (SPAD) in wheat (Triticum aestivum L.) under well-watered and drought stress conditions. J. Food Agric. and Enviroment 5, 225-227.

Kargiotidou A., Papathanasiou F. Baxevanos D., Vlachostergios D.N., Stefanou S., Papadopoulos I. (2019). Yield and Stability for agronomic and seed quality traits of common bean genotypes under Mediterranean conditions. Legume research, 42(3), 308-313.

Martinez J.P., Silva H., Ledent J.F., Pinto M. (2007). Effect of drought stress on the osmotic adjustment, cell wall elasticity and cell volume of six cultivars of common beans (Phaseolus vulgaris L.). European Journal of Agronomy 26, 30-38.

Mavromatis A.G., Arvanitoyannis I.S., Chatzitheodorou V.A., Khah E.M., Korkovelos A.E., Goulas C.K. (2007). Landraces versus commercial common bean cultivars under organic growing conditions: A comparative study based on agronomic 
performance and physicochemical traits. European Journal of Horticultural Science, 72, 214-219.

Papadopoulos I., Tokatlidis I., Tamoutsidis, E. (2004). Environmental effects on phenotypic expression are blunted in greenhouse compared to open field. In the Proceedings of the 4th International Crop Science Congress, 2004 Brisbane, Australia.

Papadopoulos I.I., Tokatlidis I.S., Koutika-Sotriou M., Tamoutsidis E., Kouroubas S. (2007). Crop yield potential estimated under too low density effectively predicts performance under dense stand in dry bean. International Journal of Plant Breeding and Genetics, 1(2), 75-81.

Papathanasiou F., Papadopoulou F., Papadopoulos I. (2018). Single-plant selection at ultra-low density of three bean cultivars and salinity tolerance during germination. Proceedings of the IX International Agricultural Symposium “Agrosym 2018”, 164169.

Soureshjani H.K., Nezami A., Kafi M., Tadayon M. (2019). Responses of two common bean (Phaseolus vulgaris L.) genotypes to deficit irrigation. Agricultural Water Management, 213, 270-279.

Teran H., Singh S.P. (2002). Comparison of sources and lines selected for drought resistance in common bean. Crop Science 42, 64-70.

Tokatlidis I.S. (2015). Conservation breeding of elite cultivars. Crop Science, 55(6), 2417-2434.

Vlahostergios D.N., Tzantarmas C., Kargiotidou A., Ninou E., Pankou C., Gaintatzi C., Mylonas I., Papadopoulos I., Foti. C., Chatzivassiliou E., Sinapidou A., Lithourgidis A., Tokatlidis I.S. (2018). Single-plant selection within lentil landraces at ultra-low density: a short-time tool to breed high yielding and stable varieties across divergent environments. Euphytica, 214 (58). 